\title{
Effects of larval age on mortality of Monochamus alternatus Hope (Coleoptera: Cerambycidae) after application of nonwoven fabric strips with Beauveria bassiana
}

\author{
Mitsuaki SHIMAZU* and Hiroki SATo \\ Forestry and Forest Products Research Institute; Tsukuba, Ibaraki 305-8687, Japan
}

(Received 28 June 2002; Accepted 2 September 2002)

\begin{abstract}
During field applications of Beauveria bassiana for control of Monochamus alternatus larvae living in dead pine trees, differences of mortalities by application date could not be analyzed due to variability in timing of oviposition. To solve this problem, pine logs with eggs of the same age were obtained by exposing logs to female beetles for one day in a screened cage in July or August. Nonwoven fabric strips impregnated with B. bassiana cultures were applied to the logs in September. Infection rate by B. bassiana was higher among larvae from eggs laid in August compared with those from eggs laid in July. Among the logs oviposited on the same day, the infection rate was higher in those with 4 strips $/ 2 \mathrm{~m}$ than those with 1.5 strips $/ 2 \mathrm{~m}$. The results of the experiment showed that control of M. alternatus by applying nonwoven fabric strips with $B$. bassiana was more effective when the fungus was applied to young larvae located under the bark instead of older larvae further within the wood.
\end{abstract}

Key words: Monochamus alternatus; Beauveria bassiana; microbial control; oviposition; larval age

\section{INTRODUCTION}

Pine wilt is the most important disease of pine trees in Japan. The pathogen causing this disease, the pinewood nematode (Bursaphelenchus xylophy$l u s)$, is transmitted by the Japanese pine sawyer, Monochamus alternatus (Coleoptera: Cerambycidae). To control this disease, chemical insecticides have been used to kill $M$. alternatus and thus prevent transmission of the pathogen. Shimazu and Kushida (1983) studied microbial control of this insect, and suggested that an entomopathogenic fungus, Beauveria bassiana shows promise as a control agent of $M$. alternatus larvae. Shimazu et al. (1995) cultured this fungus on nonwoven fabric strips, applied the strips to infested trees, and obtained relatively high mortalities of the larvae. This method of application is thought to be the most convenient and effective method for using $B$. bassiana to control M. alternatus larvae (Shimazu, 1997).

First to 3rd stadium larvae of $M$. alternatus feed on the phloem and cambium of pine trees, while 4th instars begin boring into sapwood about 35 to 45 days after oviposition (Kishi, 1995). In Ibaraki
Prefecture, approximately $10 \%, 50 \%$ and $90 \%$ of larvae completed construction of pupal chambers in the beginning of October, November and December, respectively (Kishi, 1980). Usually, nonwoven fabric strips with $B$. bassiana are applied between July and October, before larvae create tunnels and pupal chambers in the wood. Early application by this method has been thought to produce higher mortality of larvae because early instars directly beneath the bark receive more exposure to the fungus and generally young larvae are more susceptible to B. bassiana compared with old larvae (Feng et al., 1985). However, since oviposition timing of M. alternatus on dead pines in the field is not synchronous, testing the effectiveness of early versus late application has not been possible. To test this hypothesis, we exposed pine boles to $M$. alternatus adults in a screened cage for limited periods for oviposition to obtain uniform-aged larvae, and then applied nonwoven fabric strips with $B$. bassiana at two doses to compare larval mortality depending on larval age.

\footnotetext{
* To whom correspondence should be addressed at: E-mail: shimazu@ffpri.affrc.go.jp
} 


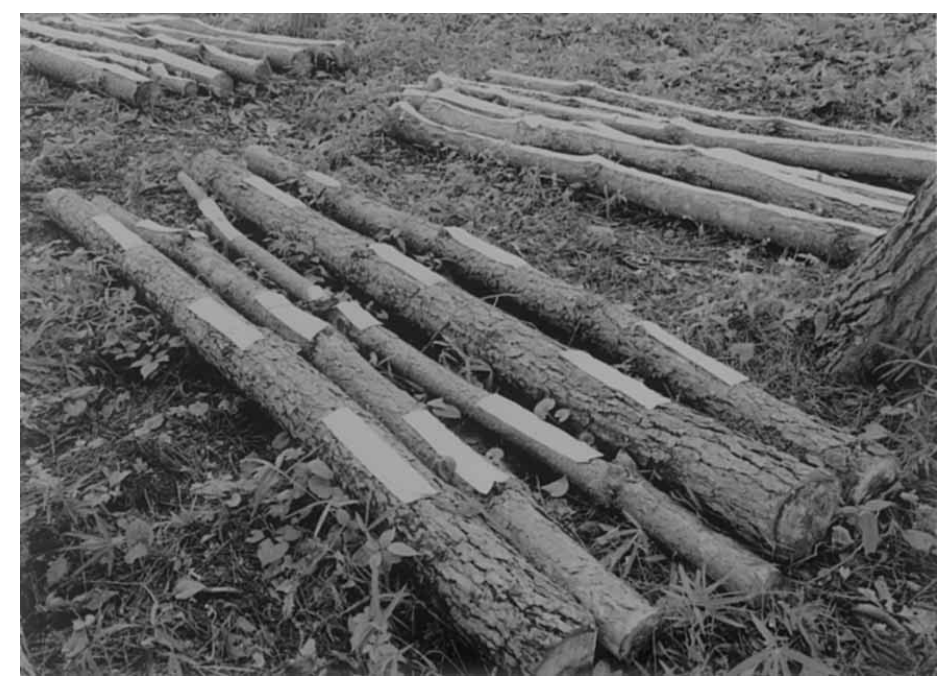

Fig. 1. Application of nonwoven fabric strips on logs of pine wilt-killed Pinus densiflora.

\section{MATERIALS AND METHODS}

To obtain fresh adults of $M$. alternatus for oviposition, pine wilt-killed Pinus densiflora trees in which M. alternatus larvae were feeding were cut down at Chiyoda, Ibaraki Prefecture, and those boles were placed in a screened cage. Emerged adults of the beetles from the pine boles were captured and reared individually in plastic cups $(11 \mathrm{~cm}$ diameter, $5 \mathrm{~cm}$ depth). One day before oviposition, the adults were placed in pairs in the cup, and females after pairing were used for oviposition.

Healthy $P$. densiflora trees at Kukisaki, Ibaraki Prefecture were felled, cut into $2 \mathrm{~m}$ long logs (middiameter: $4.8-13.7 \mathrm{~cm}$ ) and air-dried in a screened cage for oviposition. The mated females were released on the logs in the screened cage, and were allowed to deposit eggs for $24 \mathrm{~h}$. The felling of pine trees and oviposition by beetles were carried out twice; felling trees on 16 July 1997 and allowing oviposition on 28 July 1997 as the early oviposition, and felling on 4 August 1997 and allowing oviposition on 15 August 1997 as the late oviposition. The logs were placed in a screened cage after the oviposition until application of nonwoven fabric strips with $B$. bassiana to exclude wild insects.

B. bassiana $\mathrm{F}-263$ isolated from a cadaver of a M. alternatus larva from Kumamoto Prefecture was used in the experiment. This isolate is one of the most virulent to $M$. alternatus, and has been used through a series of control experiments against this insect (Shimazu and Kushida, 1980; Shimazu et al., 1982, 1983, 1992; Shimazu, 1994).

The nonwoven fabric materials $(43 \times 5 \mathrm{~cm})$ for the experiment were supplied by Nitto Denko Corporation, Osaka, Japan. The fungus was cultured on the nonwoven fabric strips according to the method of Shimazu et al. (1995) and stored in a refrigerator before use. Density of conidia on the strips was $1-2 \times 10^{8} / \mathrm{cm}^{2}$.

On 18 September 1997, the logs with M. alternatus eggs laid both on 28 July and 15 August were placed on the ground under a mixed forest of P. densiflora and Quercus serrata at Kukisaki, Ibaraki. Nonwoven fabric strips with the fungus were applied on the upper surface of the logs in parallel to the axes of the logs, and fixed in place using a staple gun (Fig. 1). On each $2 \mathrm{~m} \mathrm{log}$, four strips or $1.5(22 \mathrm{~cm}$ piece $\times 3)$ strips were applied for treatments, and no strips were applied to controls. These densities of strips were used for each oviposition period (July and August), and five to six logs were used for each experimental treatment. Logs were dissected on 26 to 27 November 1997, and numbers and mortalities of M. alternatus larvae were investigated. Dead larvae with white mycelia growing on bodies or those mummified and pale pink in color were diagnosed as infected.

\section{RESULTS}

Approximately 40 to $90 \%$ of $M$. alternatus lar- 
Table 1. Numbers and mortalities of Monochamus alternatus larvae in logs with non-woven fabric strips impregnated with Beauveria bassiana

\begin{tabular}{|c|c|c|c|c|c|c|c|c|}
\hline \multirow{3}{*}{$\begin{array}{c}\text { Date of } \\
\text { oviposition }\end{array}$} & \multirow{3}{*}{$\begin{array}{l}\text { Number of } \\
\text { strips } / 2 \mathrm{~m}\end{array}$} & \multirow{3}{*}{$\begin{array}{c}\text { Number } \\
\text { of logs }\end{array}$} & \multicolumn{4}{|c|}{ Mean number of Monochamus alternatus larvae per log } & \multirow{2}{*}{\multicolumn{2}{|c|}{$\begin{array}{l}\text { Percent infection } \\
\quad(\text { mean } \pm \text { SD })\end{array}$}} \\
\hline & & & \multirow{2}{*}{ Alive } & \multicolumn{2}{|c|}{ Dead } & \multirow{2}{*}{ Total } & & \\
\hline & & & & Infected & Others & & & \\
\hline 28 July & 0 & 5 & 20.0 & 1.6 & 0.4 & 22.0 & $7.4 \pm 5.5$ & $\mathrm{a}$ \\
\hline 28 July & 1.5 & 5 & 6.6 & 5.8 & 0.2 & 12.6 & $39.7 \pm 26.4$ & $\mathrm{~b}$ \\
\hline 28 July & 4 & 6 & 5.5 & 8.3 & 0.5 & 14.3 & $57.6 \pm 21.1$ & $\mathrm{bc}$ \\
\hline 15 August & 0 & 6 & 27.2 & 0.0 & 0.2 & 27.3 & $0.0 \pm 0.0$ & $\mathrm{a}$ \\
\hline 15 August & 1.5 & 6 & 5.5 & 20.5 & 0.8 & 26.8 & $74.2 \pm 14.5$ & $\mathrm{~cd}$ \\
\hline 15 August & 4 & 6 & 3.5 & 35.7 & 0.3 & 39.5 & $89.6 \pm 5.8$ & $\mathrm{~d}$ \\
\hline
\end{tabular}

${ }^{a}$ Means followed by the same letter were not significantly different at $p \leqq 0.05$ (Tukey-Kramer's multiple comparison test). Data were arcsine transformed before analysis and untransformed means are presented.
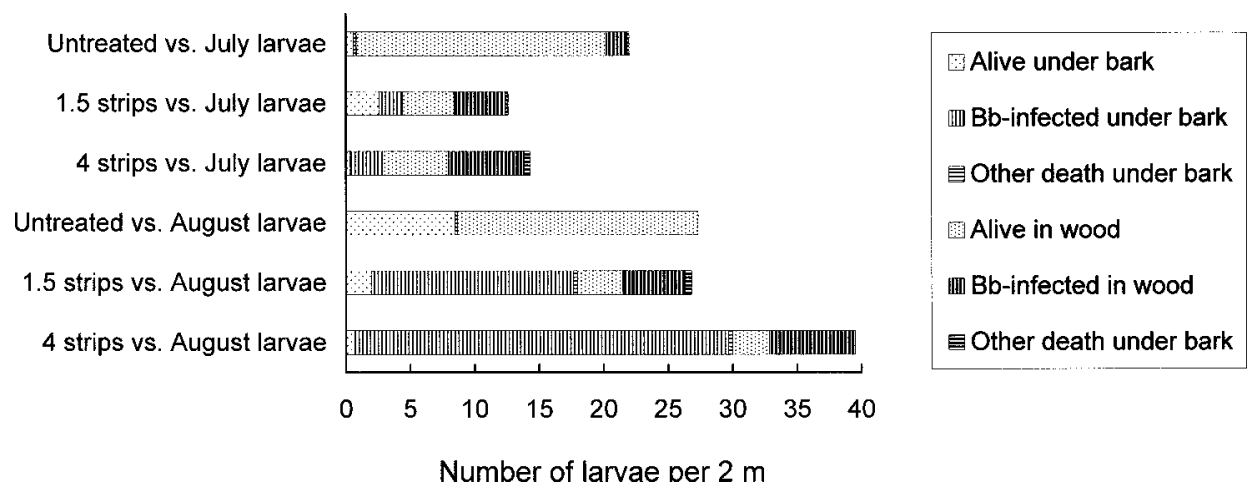

Fig. 2. Numbers and states of larvae found when dissecting logs. The vertical axis indicates the number of strips per $2 \mathrm{~m}$ and the oviposition month.

vae under the bark or in the wood of logs treated with the fungus became infected with $B$. bassiana (Table 1). Some larvae in the control plot of the early oviposition were also infected with $B$. bassiana; however, percent infections in the treatments for both strip densities were significantly higher than percent infection in the controls. Infection rates of larvae in the late oviposition plots were significantly higher than those in the early oviposition plots. Among larvae from eggs laid at the same time, percent infection for those treated with four strips tended to be higher than those treated with 1.5 strips. Most of the larvae from eggs laid in July were found in the wood when investigated by chopping logs. Within this study, percent infection was higher for larvae in the wood compared with those under the bark. On the other hand, most of the larvae from eggs laid in August were still found under the bark, and percent infec- tion under the bark was higher than percent infection for larvae in the wood (Fig. 2).

\section{DISCUSSION}

It has been known that $M$. alternatus larvae under the bark can be infected with $B$. bassiana by simply applying nonwoven fabric strips with the fungus onto the outside of the bark (Shimazu et al., 1995). The infection must be caused by encounter of the larvae with conidia that have reached the larval habitat through some route; however, it has not been experimentally confirmed. Water flow from rain or small animals inhabiting around the bark are thought to carry B. bassiana conidia from the strips to the larval habitat.

Results of field experiments to apply nonwoven fabric strips with $B$. bassiana have suggested that earlier application provides better control. When 


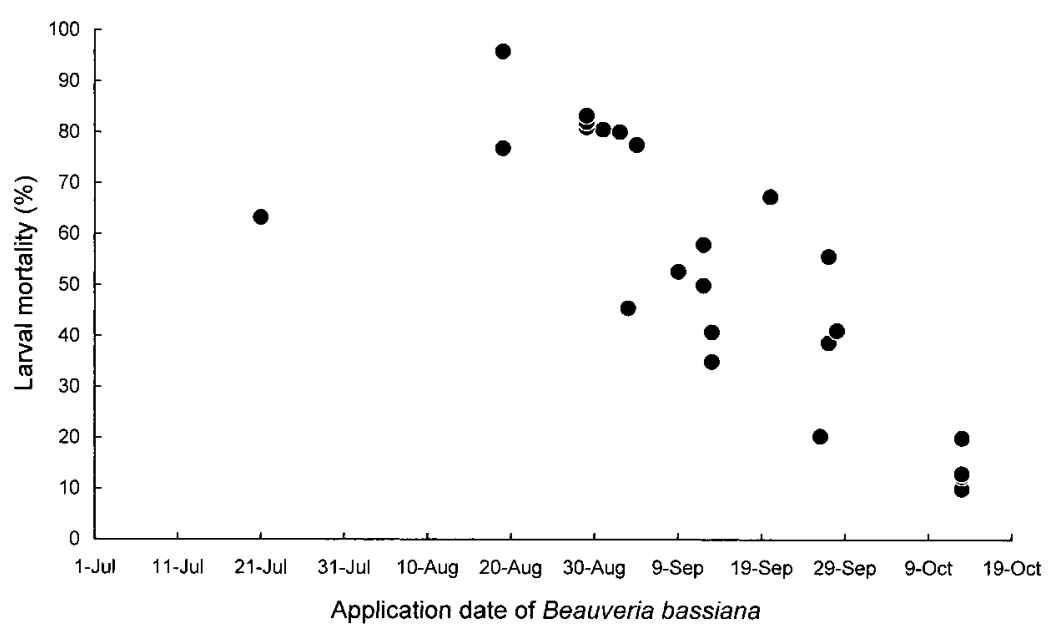

Fig. 3. Relationship between application dates of Beauveria bassiana and mortalities of Monochamus alternatus larvae.

reviewing the data obtained from a series of field experiments conducted by the Forestry Agency (1994, 1995, 1996, 1997, 1998, 1999, 2000, 2001, and unpublished), larval mortalities decreased with increasing application dates (Fig. 3), although the mortalities were often variable. This relationship between application dates and larval mortalities supports the effectiveness of early application.

The majority of larvae at early application were younger than those at late application. Young larvae are often more susceptible to B. bassiana compared with old larvae (Feng et al., 1985), while ages of adults did not affect their susceptibility to B. bassiana and Metarhizium anisopliae (Rizzo, 1977). Another possible factor explaining differential infection levels is the difference in larval behavior of M. alternatus according to age. M. alternatus larvae always live under the bark during first to third stadia, but begin to bore into the sapwood at the fourth stadium (Kishi, 1995). Thus, younger larvae have more opportunity to encounter the fungus applied onto bark than older larvae. Females of $M$. alternatus only deposit eggs on weakened or dead pine trees. During their oviposition period, pine trees weakened in March to late August used for oviposition (Okuda et al., 1975; Takeshita, 1980). For this reason, oviposition dates of M. alternatus may vary widely even within a tree, except in the case where many eggs are deposited at once. Thus, larval ages usually vary in naturally oviposited trees, and this is thought to account, in part, for the fluctuations in mortality when $B$. bassiana was applied in field.
In the present experiment, we successfully prepared logs with larvae of the same age by limiting oviposition to one day, and could obtain results showing that when the fungus was applied to the bark, more larvae from eggs laid in August were killed by the fungus than those from eggs laid in July. In other words, mortality of the young larvae was higher than that of older larvae. This demonstrates that the higher mortality obtained from practical field use of $B$. bassiana is not due to seasonal factors but to the age of the larvae. From these results, the effectiveness of the early application of nonwoven fabric strips with $B$. bassiana, and also, possibly, the non synchronized larval age as the cause of scatter of the larval mortalities under the same condition of application were experimentally proved.

In this study, larval habitat was not investigated by peeling the bark or by dissecting the wood at the moment of application. However, for the larvae from eggs laid in August, it can be assumed that most were under the bark at the moment of application because many were found there, both alive and dead when we dissected the logs. For larvae from eggs laid in July, it cannot be determined whether they were under the bark or in the wood at the time the fungus was applied. However, some of the larvae from eggs laid in July were thought to be under the bark at the time of application on 18 September, because some infected larvae were found under the bark when the logs were investigated in November.

This study has experimentally confirmed that 
when nonwoven fabric strips with $B$. bassiana are used to control $M$. alternatus larvae, application against young larvae produces a better control effect. However, in reality it will be difficult to find an infested tree with young $M$. alternatus larvae that are still under the bark, because at such a stage of pine wilt disease, infected trees still have green needles. Moreover, there is the problem that the ages of M. alternatus larvae in a wild infested tree are usually not synchronized, and larvae living under the bark and in the wood are of mixed age.

\section{ACKNOWLEDGEMENTS}

We thank Dr. Noritoshi Maehara of the Forestry and Forest Products Research Institute for the statistical analysis of data, and Dr. Yukio Takizawa of the Forestry Development Technological Institute for assistance of the field investigations. We also thank Dr. Ann E. Hajek of Cornell University for reviewing the manuscript and correcting the English.

\section{REFERENCES}

Feng, Z., R. I. Carruthers, D. W. Roberts and D. S. Robson (1985) Age-specific dose-mortality effects of Beauveria bassiana (Deuteromycotina: Hyphomycetes) on the European corn borer, Ostrinia nubilalis (Lepidoptera: Pyralidae). J. Invertebr. Pathol. 46: 259-264.

Forestry Agency (1994) Reports on Researches Commissioned for 1993. Biological Control of Pine Wilt Disease. The Forestry Development Technological Institute, Tokyo. 60 pp. (in Japanese).

Forestry Agency (1995) Reports on Researches Commissioned for 1994. Biological Control of Pine Wilt Disease. The Forestry Development Technological Institute, Tokyo. 32 pp. (in Japanese).

Forestry Agency (1996) Reports on Researches Commissioned for 1995. Biological Control of Pine Wilt Disease. The Forestry Development Technological Institute, Tokyo. 50 pp. (in Japanese).

Forestry Agency (1997) Reports on Researches Commissioned for 1996. Biological Control of Pine Wilt Disease. The Forestry Development Technological Institute, Tokyo. 47 pp. (in Japanese).

Forestry Agency (1998) Reports on Researches Commissioned for 1997. Biological Control of Pine Wilt Disease. The Forestry Development Technological Institute, Tokyo. 66 pp. (in Japanese).

Forestry Agency (1999) Reports on Researches Commissioned for 1998. Biological Control of Pine Wilt Disease. The Forestry Development Technological Institute, Tokyo. 70 pp. (in Japanese).

Forestry Agency (2000) Reports on Researches Commissioned for 1999. Biological Control of Pine Wilt Disease. The Forestry Development Technological Institute, Tokyo. 48 pp. (in Japanese).

Forestry Agency (2001) Reports on Researches Commissioned for 2000. Biological Control of Pine Wilt Disease.
The Forestry Development Technological Institute, Tokyo. 56 pp. (in Japanese).

Kishi, Y. (1980) Mortality of pine trees by Bursaphelenchus lignicolus M. \& K. (Nematoda: Aphelenchoidae) in Ibaraki Prefecture and its control. Bull. Ibaraki Pref. For. Exp. Stn. 11: 1-88 (in Japanese with English summary).

Kishi, Y. (1995) The Pine Wood Nematode and the Japanese Pine Sawyer. Thomas Company Limited, Tokyo. $302 \mathrm{pp}$.

Okuda, M., R. Hosoda, K. Kobayashi and F. Yamada (1975) Felling timing of three species of pine and infestation degree of Monochamus alternatus. Trans. 86th Meet. Jpn. For. Soc., 331-332 (in Japanese).

Rizzo, D. C. (1977) Age of three dipteran hosts as a factor governing the pathogenicity of Beauveria bassiana and Metarhizium anisopliae. J. Invertebr. Pathol. 30: 127-130.

Shimazu, M. (1994) Potential of the cerambycid-parasitic type of Beauveria brongniartii (Deuteromycotina: Hyphomycetes) for microbial control of Monochamus alternatus Hope (Coleoptera: Cerambycidae). Appl. Entomol. Zool. 29: 127-130.

Shimazu, M. (1997) Recent researches on microbial control of Monochamus alternatus using entomogenous fungi and its safety. Forest Pests 46: 107-114 (in Japanese).

Shimazu, M. and T. Kushida (1980) Microbial control of Monochamus alternatus - Treatment of pathogens on the infested pine trees-. Trans. 32nd Meet. Kanto Branch Jpn. For. Soc., 93-94 (in Japanese).

Shimazu, M. and T. Kushida (1983) Virulences of the various isolates of entomogenous fungi to Monochamus alternatus Hope. Trans. 35th Meet. Kanto Branch Jpn. For. Soc., 165-166 (in Japanese).

Shimazu, M., T. Kushida and K. Katagiri (1982) Microbial control of Monochamus alternatus - Spray of pathogens onto the infested pine trees just before adult emergence. Trans. 93rd Meet. Jpn. For. Soc., 399-400 (in Japanese).

Shimazu, M., T. Kushida and K. Katagiri (1983) Microbial control of Monochamus alternatus-Spraying of pathogens during maturation feeding. Trans. 94th Meet. Jpn. For. Soc., 485-486 (in Japanese).

Shimazu, M., T. Kushida, D. Tsuchiya and W. Mitsuhashi (1992) Microbial control of Monochamus alternatus Hope (Coleoptera: Cerambycidae) by implanting wheatbran pellets with Beauveria bassiana in infested tree trunks. J. Jpn. For. Soc. 74: 325-330.

Shimazu, M., D. Tsuchiya, H. Sato and T. Kushida (1995) Microbial control of Monochamus alternatus Hope (Coleoptera: Cerambycidae) by application of nonwoven fabric strips with Beauveria bassiana (Deuteromycotina: Hyphomycetes) on infested tree trunks. Appl. Entomol. Zool. 30: 207-213.

Takeshita, T. (1980) Felling timing of small-sized Pinus thunbergii and infestation of Monochamus alternatus and Bursaphelenchus xylophylus. Trans. 31st Meet. Kansai Branch Jpn. For. Soc., 233-235 (in Japanese). 